\title{
Language profile and syntactic change in two multilingual communities
}

\author{
Ariana Bancu*
}

\begin{abstract}
This paper explores variables that can explain contact-induced linguistic variation and change in a situation where diachronic data is lacking and number of speakers is small. For example, in contexts involving language endangerment traditional sociolinguistic variables such as age, gender, and social class will not apply due to small number of participants. Furthermore, additional sociolinguistic variables such as degree of language use, language attitudes, etc. are needed to explaining contact-induced variation. The target language is Transylvanian Saxon (hereafter TrSax), an endangered language that coexists with German and Romanian in Romania and in émigré communities in Germany. I collected sociolinguistic and questionnaire data from two groups of trilingual speakers of TrSax, German, and Romanian. Six participants are from Viscri, Romania and six participants are part of a community of Transylvanian Saxons from Viscri, who moved to Nuremberg, Germany approximately 30 years ago. I illustrate the methodology I used for identifying the variables that distinguish the two groups and I discuss how these variables can be applied to analyze contact-induced variation in $\operatorname{TrSax}$ on hand of preliminary production data.
\end{abstract}

Keywords: language contact; sociolinguistics; multilingualism; language dominance; language attitudes; Transylvanian Saxon

1. Introduction. There is growing interest in explaining variation in endangered languages by using variationist sociolinguistic approaches and applying them to naturalistic production data (Nagy 2017). Often sociolinguistic approaches to variation focus primarily on monolingual populations, and endangered languages rarely exist in the absence of multilingualism. It is therefore important to understand the interaction between variation and multilingualism in cases of endangered languages, and to have detailed information on speakers and their degree of access to the languages in contact (Kantarovich and Grenoble 2017). The purpose of this paper is to take the first step towards explaining contact-induced variation in Transylvanian Saxon (TrSax) by presenting a methodology used to capture the relationship between speakers and the languages they use. I recorded production data in TrSax through sociolinguistic interviews and gathered detailed information on participants' linguistic background. I also administered a modified version of the Bilingual Language Profile (BLP) questionnaire (Gertken et. al 2014) in order to capture different dimensions of language dominance, such as language use, language proficiency and attitudes towards the languages participants speak.

\footnotetext{
* I would like to thank the University of Michigan for the various sources of funding that supported this research, in particular the Linguistics Department, the Rackham Graduate School, and the Center for Russian, East European, and Eurasian Studies (CREES). I thank my advisor Marlyse Baptista for her invaluable input, Robin Queen for encouraging me to pursue this research, my colleagues in the Linguistics department and others who attended talks I gave at conferences and provided oral input. I thank I am especially grateful to my Transylvanian Saxon participants and RAs who made this work possible in the first place. Authors: Ariana Bancu, University of Michigan(abancu@umich.edu).
} 
TrSax is an endangered Germanic language that coexists with German and Romanian in Romania and émigré communities in Germany. There are 240 localities in Romania where dialects of TrSax are spoken and there is variation among dialects at the phonological, lexical, and morphosyntactic level (Sift 2015:190). The patterns of syntactic variation I report on in this paper, while not restricted to this dialect, are based on production data I collected from speakers in Viscri, a multiethnic village in Romania. It is not clear at the time how this type of variation extends to different dialects of TrSax, thus I will refer to the variety in this study as Viscri Saxon. I present data from 12 trilingual Transylvanian Saxons from Viscri, who learned TrSax as their first language, Standard German second, and Romanian third. Six of the participants were recorded in Viscri, and six participants were recorded in Nuremberg, Germany. The latter six participants left Viscri about 30 years ago and immigrated to the Nuremberg area in Germany where they are active members of a community of Transylvanian Saxons from Viscri. Participants from the two sites are very cohesive in many aspects and share a similar background, yet differ in terms of language exposure and language use (i.e. participants in Romania are exposed to and use more Romanian, participants in Germany are exposed to and use more German). Data from the homeland and diaspora communities are compared for two reasons: first to identify the potential variables that set the two communities apart (i.e. degree of language use, language attitudes); and second to test if these variables influence the patterns of verb complex variation encountered in a subset of individual speakers.

In an initial investigation I conducted with six participants from Viscri, I found that word order variation was present in Viscri Saxon subordinate clauses that contained a verbal complex formed of an auxiliary or modal and a lexical verb. Such constructions, known as two-verb complexes (Dubenion-Smith 2010) or two-verb clusters (Wurmbrand 2015), are formed of an auxiliary/modal and a lexical verb that occur adjacent to each other in subordinate clauses. For ease of exposure I will refer to the targeted verbal complexes as Aux $+\mathrm{V}$ constructions. Such constructions changed in TrSax from a fixed Aux-V order (Holzträger 1912:28) to flexible Aux$\mathrm{V} / \mathrm{V}$-Aux order under the influence of Standard German ${ }^{1}$, which requires the verb to precede the auxiliary/modal in subordinate clauses (Sapp 2011:1). The examples shown below come from the same speaker from Viscri (participant P4 in Figure 1) and show the two possible orders in TrSax: in (1) the native TrSax structure where the auxiliary (hun 'have') precedes the verb (gemacht 'made') and in (2) the German-type structure where the verb (verkeuft 'sold') precedes the auxiliary (hun 'have').

$$
\begin{aligned}
& \text { Viscri Saxon (Aux-V) } \\
& \text {... anj esi [wa mer et } \text { hun }_{\text {Aux }} \text { gemacht }_{\mathbf{v}} \text { ] } \\
& \text { always so like we it have.1PL make.PTCP } \\
& \text { '(The bread they make is) always the way that we have made it.' } \\
& \text { Viscri Saxon (V-Aux) } \\
& \text {...dat ech sa verkeuft } \text { hun } \text { hux }_{\text {Aux }} \\
& \text { that I them sell-PCPT have.1SG.PRS } \\
& \text { '(I was glad) that I sold them.' }
\end{aligned}
$$

An in-depth analysis based on production data from the six participants in Viscri revealed that these structures were in free variation. There were no linguistic factors (i.e. type of verb, type of auxiliary or modal, type of subordinating conjunction, etc.) that could explain when each struc-

\footnotetext{
${ }^{1}$ Standard German has been traditionally used in TrSax communities as a literary language, learned in a formal setting, as it is the primary language for education.
} 
ture was used (Bancu 2017), but significant differences could be determined in the way individual participants used these constructions. Speakers who used three languages regularly used both TrSax and German-type structures, while speakers who used only two languages used only one of the two possible structures. These results are summed up in Figure 1 below: participant P1, who is a TrSax-German bilingual, uses only German-type structures (V-Aux), while participant P5, who is a TrSax-Romanian bilingual uses only TrSax structures (Aux-V). The y-axis shows the proportion for each construction and the x-axis shows the participants, with the languages they speak listed under the participants in order of use, i.e. most use language occurs on top.

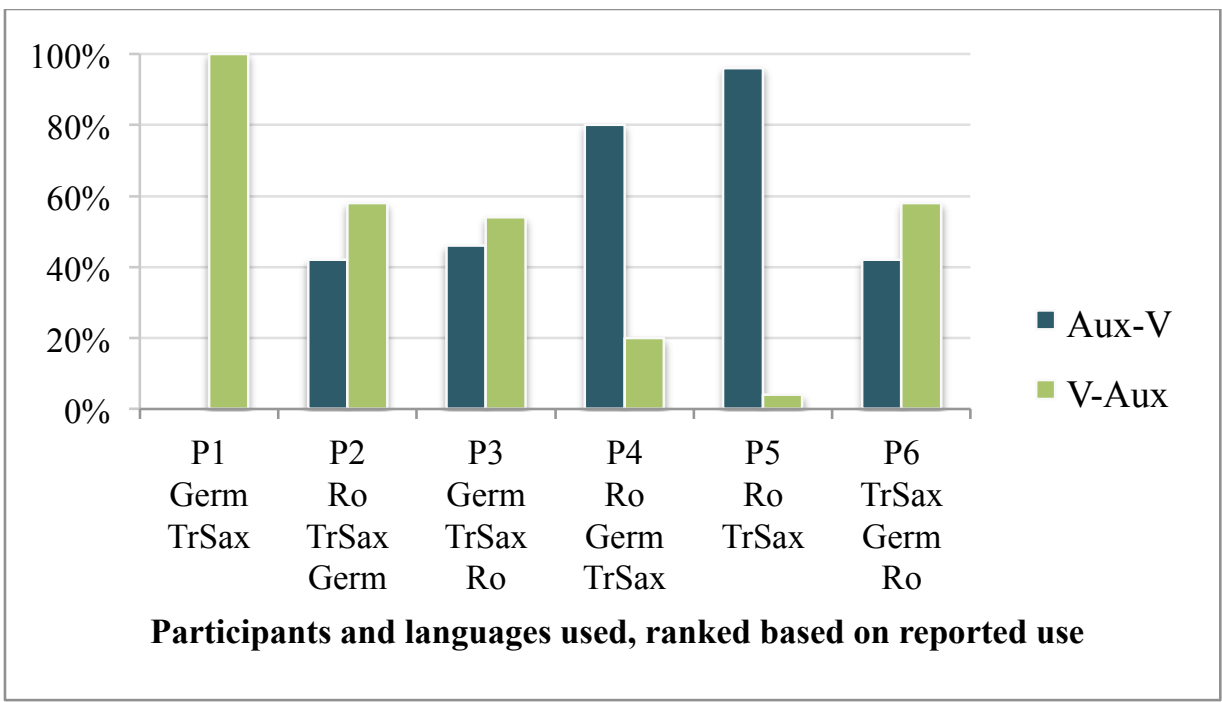

Figure 1. Distribution of Aux-V/V-Aux $(n=154)$ based on 6 participants from Viscri, Romania The results presented above indicate that there is a connection between the languages a participant speaks and the distribution of Aux-V/V-Aux orders s/he uses in Viscri Saxon subordinate clauses, however further data is needed to corroborate these findings. In this paper I present additional production data from 4 more participants and discuss in more detail results from a language profile questionnaire participants filled out.

I hypothesize that participants who use more German will show more German influence in TrSax, i.e. more V-Aux structures, than participants who use more Romanian. However, if language use cannot be linked to the distribution of native and transferred structures, speakers' attitudes towards the languages in the community (cf. Thomason 2010, Nagy et al. 2011) could account for the encountered patterns of variation: speakers who show more positive attitudes towards TrSax than towards German and Romanian will use more of the native Aux-V structures in TrSax. Thus, in this paper I discuss how to identify the variables that can explain the connection between the patterns of variation and the languages a participant speaks on hand of additional data I collected, and propose avenues for future research.

2. Background. Transylvanian Saxons settled in Romania in the 12 th century AD coming from the Rhine and Moselle regions in Germany. TrSax is considered an outlying dialect of Moselle Franconian (Luxembourgish), spoken by approximately 50,000 people in the world originating from Transylvania ${ }^{2}$. The well-educated Transylvanian Saxons studied at German universities in

\footnotetext{
2 According to UNESCO Atlas of the World's Languages in Danger: http://www.unesco.org/languagesatlas/en/atlasmap/language-id-1475.html
} 
Halle, Leipzig, and other cities in Germany as early as the 15 th century AD, thus reinforcing the contact between TrSax and German among the elites. While official documents were held in Latin at first, German was adopted as an official written language with the reformation of the Lutheran church (16th century). The contact with German intensified over time among all social classes, especially with Transylvania becoming part of the Austro-Hungarian Empire (18th century). TrSax was replaced at that time with Hochdeutsch 'Standard/ High German' for all official purposes, including written documents. More recent events, starting with the end of World War II, lead to the decimation of TrSax inhabitants in Romania. Due to their German heritage, many Transylvanian Saxons were sent to Russia to work as a way to repay the war debt incurred by Romania. Others retreated with the German army to escape deportation, and many more left Romania in the years immediately after the revolution in 1989 to reunite with family members that already immigrated to Germany (Bottesch 2007:344). With the industrialization process started by the communist regime in Romania many Transylvanian Saxons mobilized from the villages to the cities for work. A more intense contact with Romanian happens when Transylvanian Saxons are sent to work on cooperative state farms, where they come in closer contact with Romanians (McClure 1973). Before these events, most Transylvanian Saxons used Romanian solely to communicate with other people in the wider community when necessary, and had limited knowledge of Romanian. Furthermore, they used to be a strict endogamous community, allowing marriage only between Transylvanian Saxons and favoring marriage with Transylvanian Saxons within the same village.

Viscri, the village where the participants in this study are from, is a multi-ethnic village historically inhabited by Transylvanian Saxons, ethnic Romanians, and ethnic Roma. The number of Transylvanian Saxons in Viscri plummeted from 279 (in 1989) to only 30 in 1993 (Corsale and Iorio 2013), and to 15 in 2015, when I conducted my initial investigation. Despite the decrease in TrSax population, Viscri has been able to exploit its identity as a TrSax village through tourism. Thus, Transylvanian Saxons remain at the top of the hierarchy in Viscri, attracting tourists and providing economic opportunities for the other inhabitants. The participants interviewed for this study report that before 1989 languages were compartmentalized as follows among Transylvanian Saxons in Viscri: TrSax was the dominant language in the village, used in the home and in the wider community; German was used in school and church, and Romanian was used at work or for limited communication purposes in the village. The TrSax speakers who currently reside in Viscri have increased their use of Romanian over the past 30 years, and Romanian or German are now used as the family languages along or instead of TrSax. Participants from the immigrant community in Germany report increased use of German in the past 30 years, and very little to no use of Romanian. Interestingly, all the participants from Germany still use TrSax at home with their partners and children, and some of them report using German with their children as well. Therefore, one of the main differences between the two groups of trilinguals is in the use of Romanian and German, however some differences might occur in the use of $\operatorname{TrSax}$ as well.

3. Contact-induced variation. When two or more languages come in contact, the transfer of linguistic features from one or more source languages to one or more receiving languages is likely. Transfer has been discussed extensively in studies of language contact where two (Backus et al 2011, Baptista et al 2016), three (Clyne 2003), or more languages coexist (Gumperz and Wilson 1971, Haig 2006). For example, Clyne (2003) showed that linguistic features, which are shared between two of the languages of a trilingual are likely to spread to the third language, thus leading to an overgeneralization of the most commonly encountered features (regardless of order 
of acquisition of the three languages). Furthermore, it has been argued that transferred forms from a source language into a receiving language may be adapted differently by members of a community depending on their degree of bilingualism (Heath 1984:371). For example, first generation German immigrants in Australia had little to no English influence in their German when looking at how constituents aligned in the clause, while second- and later-generation Germans showed more English influences in their German (Clyne 2003). These findings are not surprising since second- and later-generation immigrants will be more proficient in the dominant language of the community and less proficient in the heritage language (HL).

Similarly, Nagy and Kochetov (2013) analyzed HL production data from different generation speakers of Italian, Russian, and Ukrainian living in Toronto, Canada and found generational effects, but not in all groups of HL speakers. They measured VOT length in word initial and syllable initial position and administered an Ethnic Orientation Questionnaire (EOQ) to test whether a stronger ethnic orientation (i.e. higher scores) towards the HL will correlate with shorter VOTs (i.e. less English influence). Overall their findings showed that the less participants used the HL, the more English-like VOTs they had, but not all groups behaved in a similar way. Russian and Ukrainian speakers showed more English influence with each successive generation and there was a correlation between lower EOQ scores and longer VOTs. However Italian participants showed no English influences across different generations and no correlation was found between EOQ score and length of VOT. Nagy and Kochetov (2013) attributed these results to the fact that Italian speakers of different generations had more access to the language in Toronto and use it more than speakers of Russian and Ukrainian. These results also indicate that HL speakers with positive attitudes towards the HL and increased use of the HL are able to withstand influences from the dominant language in the community.

When contact-induced changes occur in a language, variation between the new and native forms is not uncommon and there is growing interest in explaining and documenting variation in endangered languages (Kantarovich and Grenoble 2017, Meyerhoff 2015). Nagy et al (2017) took a variationist approach to analyzing null subjects in several varieties of Faetar (Francoprovençal, Italy) and compared the homeland variety to the heritage language variety in Toronto, Canada in order to detect contact-induced changes in each variety. The influence of Italian would be reflected in a high rate of null subjects, while influences from English would be reflected in a high rate of overt subjects. Both homeland and heritage Faetar are moving in the same direction towards a lower rate of null subjects especially prevalent in younger generations, and the grammatical factors that were included in the analysis had similar effects in both varieties. These findings indicate that Faetar grammar is resisting changes under the influences of Italian and English and young speakers in both sites are distancing themselves from Italian (which is widely spoken in the Faetar community in Toronto) in order to mark their Faetar identity.

While findings from the studies mentioned above lead to a closer understanding of factors influencing variation in endangered languages, some sociolinguistic variables (e.g. age, gender, social class) may not be applicable in cases where only a few speakers remain, or cases where only older generations speak the language. For example, an apparent time language change study (cf. Tagliamonte and D'Arcy 2007) is not feasible in Viscri because there are only 15 TrSax speakers left, 8 have been interviewed, and age was not a significant factor when looking at the distribution of Aux-V/V-Aux constructions. Comparing data from participants from three generations no significant differences could be identified (see results for P2 - age 30, P3 age 45, P6 - age 75 in Figure 1). It might make sense to compare TrSax - German to TrSax Romanian bilinguals to understand how exactly German and Romanian are influencing variation 
in TrSax, but TrSax - Romanian bilinguals are virtually non-existent. There is a long-standing tradition for Transylvanian Saxons to go to German schools in Romania, and Standard German is learned before Romanian.

There are several challenges in identifying the variables that will show significant differences between TrSax speakers from two locations and explain the distribution of Aux-V and VAux constructions in subordinate clauses. However, generational effects on language variation such as the ones discussed in Meyerhoff (2015) or Nagy and Kotchekov (2013) are connected to language proficiency and language attitudes, i.e. younger speakers show more contact effects in the HL because they are less proficient in the HL, have positive attitudes towards the dominant language in the community and use it more than the HL. Thus, I focus on the following variables that apply across speakers of different ages and backgrounds: language use, language attitudes, and language proficiency.

\section{Methods.}

4.1. DATA COLLECTION AND PARTICIPANTS. The data used in this study come from sociolinguistic interviews conducted with 12 Transylvanian Saxons originating from Viscri, Romania. Six participants were recorded in Viscri, Romania (participants labeled with A in Table 1) and six participants were recorded in the Nuremberg area in Germany (participants labeled with B in Table 2).

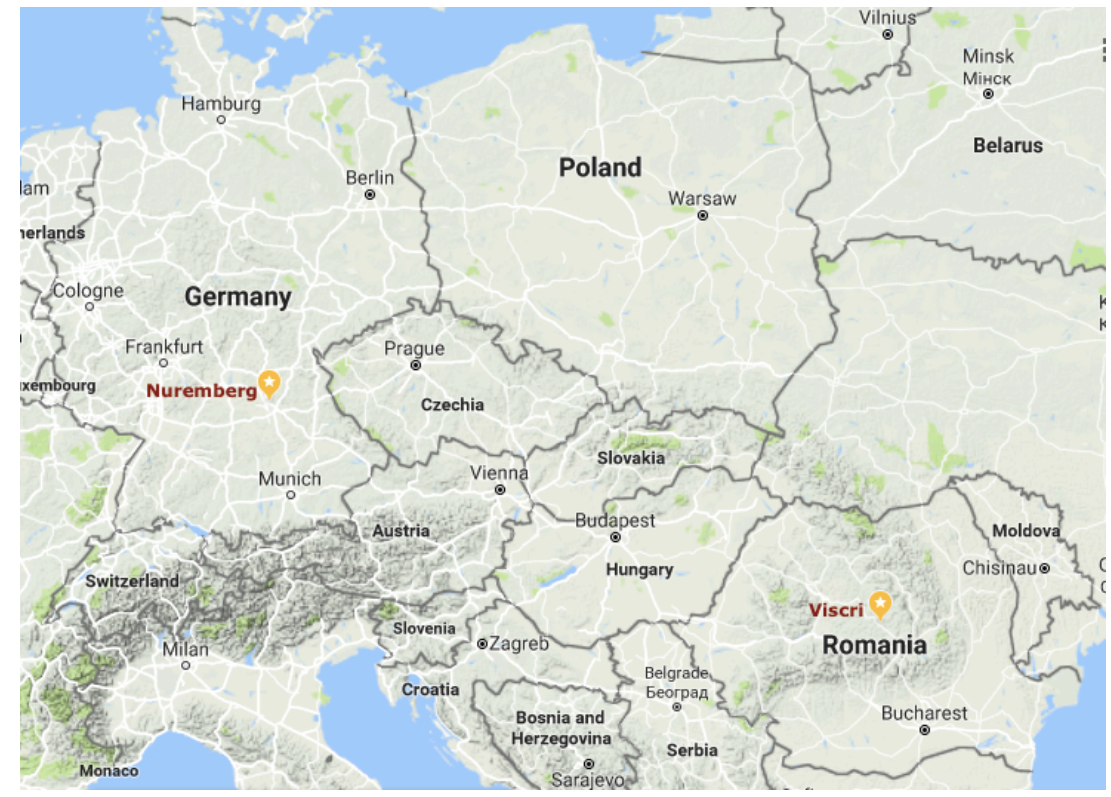

Figure 2. Locations of fieldsites for data collection: Viscri, Romania and Nuremberg, Germany

Participants were recruited using a snowball technique: an initial contact in each site identified potential participants, who in their turn identified other participants. The main selection criteria were that participants were born in Viscri, learned TrSax as their first language, and were comfortable holding a one-hour long conversation in TrSax, German, and Romanian, thus ensuring that they all had knowledge of the same three languages. Furthermore, all participants in Germany have lived there for at least 25 years (the earliest reported age at immigration was 16). A more detailed overview of the participants from each site and their linguistic background is shown in Tables 1 and 2 below: 


\begin{tabular}{|ccc|ccc|c|}
\hline \multicolumn{2}{|c|}{$\begin{array}{c}\text { PARTICIPANTS IN VISCRI } \\
\text { (SITE A) }\end{array}$} & \multicolumn{2}{c|}{$\begin{array}{c}\text { LANGUAGES: AGE WHEN } \\
\text { ACQUISION STARTED }\end{array}$} & \multirow{2}{*}{ HOME } \\
\cline { 1 - 5 } PARTICIPANT & AGE & GENDER & TRSAX & GERMAN & ROMANIAN & \\
\hline A1 & 30 & F & Since birth & 3 & 6 & Romanian/ TrSax \\
\hline A2 & 40 & M & Since birth & 3 & 7 & Romanian/ TrSax \\
\hline A3 & 47 & F & Since birth & 5 & 7 & German/ TrSax \\
\hline A4 & 58 & F & Since birth & 7 & 7 & TrSax \\
\hline A5 & 60 & F & Since birth & 6 & 7 & Romanian \\
\hline A6 & 78 & F & Since birth & 8 & 9 & TrSax \\
\hline
\end{tabular}

Table 1. Overview of participants from Viscri, Romania

\begin{tabular}{|ccc|ccc|c|}
\hline \begin{tabular}{|c|c|c|c|c|} 
PARTICIPANTS IN NUREMBERG \\
(SITE B)
\end{tabular} & \multicolumn{2}{c|}{$\begin{array}{c}\text { LANGUAGES: AGE WHEN } \\
\text { ACQUISITION STARTED }\end{array}$} & \multirow{2}{*}{$\begin{array}{c}\text { HOME } \\
\text { LANGUAGE }\end{array}$} \\
\cline { 1 - 4 } PARTICIPANT & AGE & GENDER & TRSAX & GERMAN & ROMANIAN & \\
\hline B1 & 44 & M & Since birth & 3 & 7 & TrSax/ German \\
\hline B2 & 49 & F & Since birth & 3 & 5 & TrSax \\
\hline B3 & 55 & F & Since birth & 5 & 7 & TrSax/ German \\
\hline B4 & 58 & M & Since birth & 7 & 7 & TrSax \\
\hline B5 & 65 & M & Since birth & 7 & 5 & TrSax/ German \\
\hline B6 & 75 & F & Since birth & 7 & 7 & TrSax \\
\hline
\end{tabular}

Table 2. Overview of participants from Nuremberg, Germany

Participants share a very similar language acquisition background, which is a result of their upbringing in Viscri, Romania. TrSax was acquired from birth, German was acquired as early as the age of 3 in a kindergarten or a school where German was the language of instruction, and Romanian was mainly acquired once speakers started school. However, the schools visited by all participants had German as the language of instruction and Romanian was offered as a foreign language (up to four hour instruction/ week) ${ }^{3}$.

Participants were recorded in each of the languages they speak, following a similar procedure: speakers were asked broad questions about their daily activities, events from their past, etc. (cf. Tagliamonte, 2006), and more specific questions about their language background and language use. The TrSax interviews were conducted by a research assistant, and the German and Romanian interviews were conducted by myself. Two types of data were extracted from the interviews. First, the TrSax production data was transcribed by a native TrSax speaker in ELAN (Wittenburg et al. 2006). All subordinate clauses that contained Aux $+\mathrm{V}$ constructions and were introduced by a subordinating conjunction or a relative pronoun ${ }^{4}$ were selected and the order of the Aux $+\mathrm{V}$ construction was marked (resulting in 207 tokens). Proportions for each construction (i.e. Aux-V, V-Aux) were calculated to determine how each construction is used by individual participants. An exact binomial test was performed in $\mathrm{R}$ to determine significant differences between the rates of use of one construction versus the other ${ }^{5}$. Second, information from the TrSax,

\footnotetext{
${ }^{3}$ Transylvanian Saxons are considered a German minority in Romania, and it is very common for them to visit schools where the language of instruction is Standard German. Romanian is offered as a foreign language in such schools and instruction in Romanian is available 2-4 hours/ week.

${ }^{4}$ Subordinate clauses of the type 'She said she had to go' that are not introduced by a relative pronoun or subordinating conjunction maintain 1-2 order in Standard German (Dubenion-Smith, 2008:78; Saap, 2011:2) and were thus excluded.

${ }^{5}$ The tokens were also coded for conditioning grammatical factors, such as type of verb, type of auxiliary, type of subordinating conjunction, etc. None of the analyzed grammatical factors favored one order over the other. More details are available in Bancu (2017).
} 
German, and Romanian data were used to assess participants' linguistic history, and how their use of each of the languages they speak has changed after the mass migrations of TrSax speakers from Viscri to Germany.

4.2. SURVEYS The Bilingual Language Profile (BLP) questionnaire (Gertken et al 2014) was administered to gather data about the participants' language acquisition history (e.g. age when acquisition started, years of schooling in each language), proficiency in each language (self-rated by participants on a 6 point Likert-scale based on reading, listening, and writing skills), language use (based on percent each language is used on a weekly basis at home, at work, etc.), and language attitudes (self-rated by participants on a 6 point Likert-scale) ${ }^{6}$. A global language dominance score is calculated for each language by weighing in each module of the questionnaire and individual modules can be analyzed separately as well. The maximum language dominance score a participant can receive for a language is 218 and in general the higher the score for a given language, the more dominant the speaker is in that language. Linear mixed effects analyses (lmer) were performed in $\mathrm{R}$ to assess the effect of site on individual questionnaire modules (fixed effects - Language and Site; random effects - Participant and Module Scores) in order to identify the modules that are different between the two sites. I ran a model that included the interaction between site and module score, and a model without the interaction, and compared the two models using ANOVA. Module scores were also compared by running the linear mixed effects model with each language as a reference (and computing t-scores to $\rho$ values) in order to detect the language(s) where participants scored significantly different.

\section{Results and discussion.}

5.1. QUESTIONNAIRE SCORES. I will start by discussing the aggregate language dominance scores from the BLP in each site. When comparing group means to each other, the scores indicate that groups are very similar in terms of TrSax, but differ when it comes to German and Romanian. Participants in Nuremberg obtain on average higher scores for German (169 points) than participants in Viscri (132 points), and participants in Viscri obtain on average higher scores for Romanian (160 points) as compared to participants in Nuremberg (110 points). The mean language dominance scores are captured in Figure 3, where the y-axis shows the BLP scores and the $\mathrm{x}$-axis indicates the three different languages:

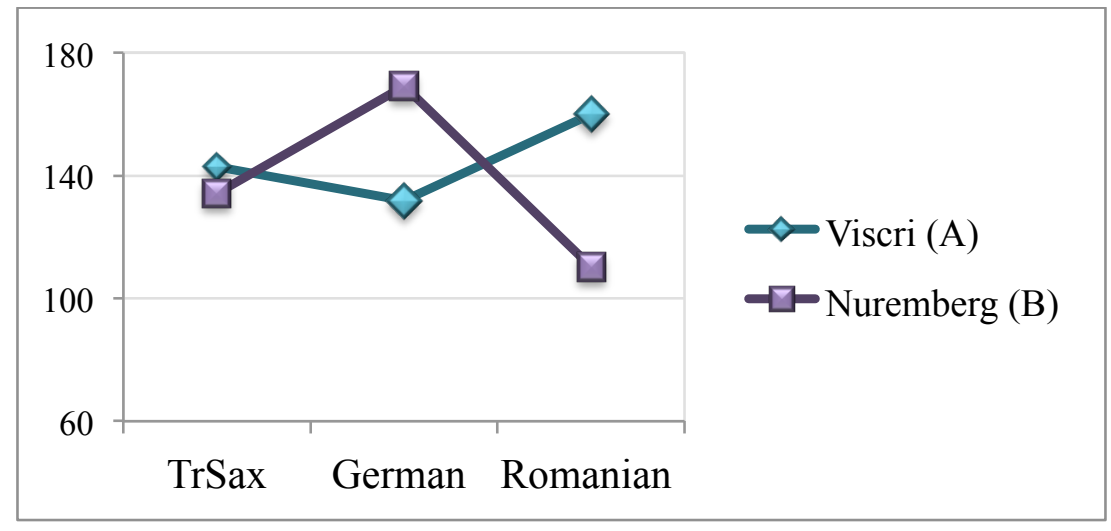

Figure 3. Mean Language Dominance Scores

\footnotetext{
${ }^{6}$ The BLP was adapted to capture three languages, instead of two as it is originally designed.
} 
Several sub-modules of the BLP, i.e. language use, language proficiency, and language attitudes, were analyzed separately in linear mixed effects analyses in R (fixed effects - Language and Site; random effects - Participant and Module Scores) to determine if participant scores were significantly different on the questionnaire modules between the two sites.

Participants from both sites scored very similarly in the Language Attitudes module and no interaction was detected between Site and Language (chi squared $=1.98, \rho=.37$ ). Ten out of twelve participants assigned a score of 6 on the Likert scale (the maximum possible) to TrSax and TrSax was ranked highest in terms of positive attitudes in both Sites, as can be seen in Figure 3 below. Furthermore, German is ranked second and Romanian third in terms of attitudes in both sites.

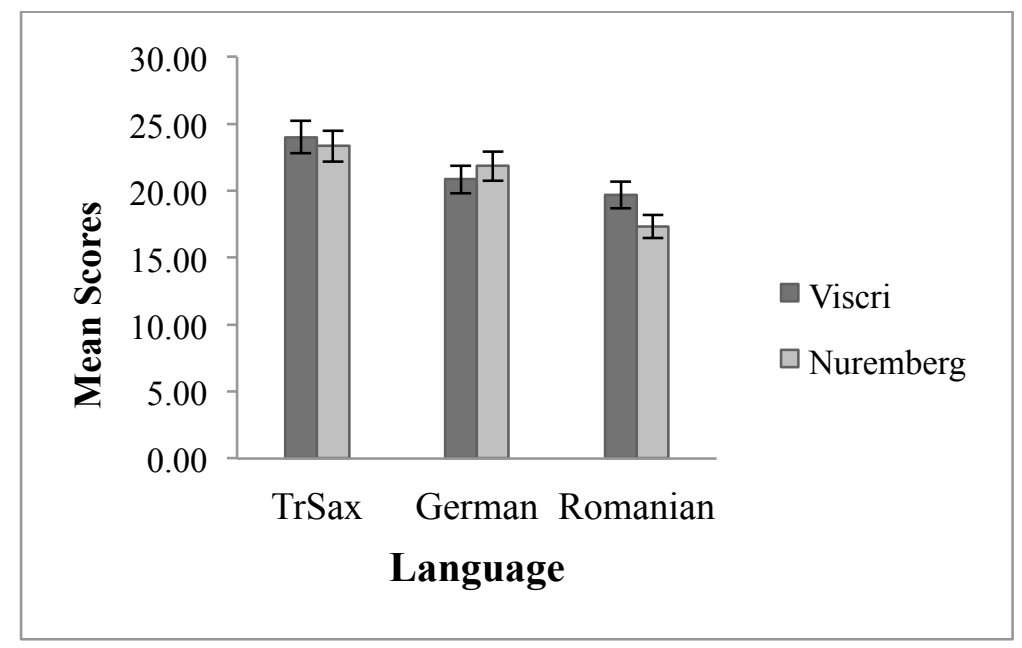

Figure 4. Mean Language Attitude scores by site

Interestingly, there are no significant differences between scores for Romanian in Visci and Nuremberg, indicating that participants from the immigrant community in Nuremberg maintain positive attitudes towards Romanian, despite their low ranking of Romanian in terms of selfassessed proficiency, and their very limited use of the language as will become clear in the following sections.

No significant interaction between Site and Language (chi squared $=4.27$ and $\rho=.12$ ) was detected for self-assessed Proficiency, however significant effects were detected for TrSax $(\rho=.03)$ and for Romanian $(\rho=.04)$ when comparing the proficiency scores for each language by site (but not German, $\rho=.06$ ). Figure 4 below reveals that participants in both sites score lowest for TrSax in terms of proficiency and participants in Nuremberg rank themselves lower than participants in Viscri. 


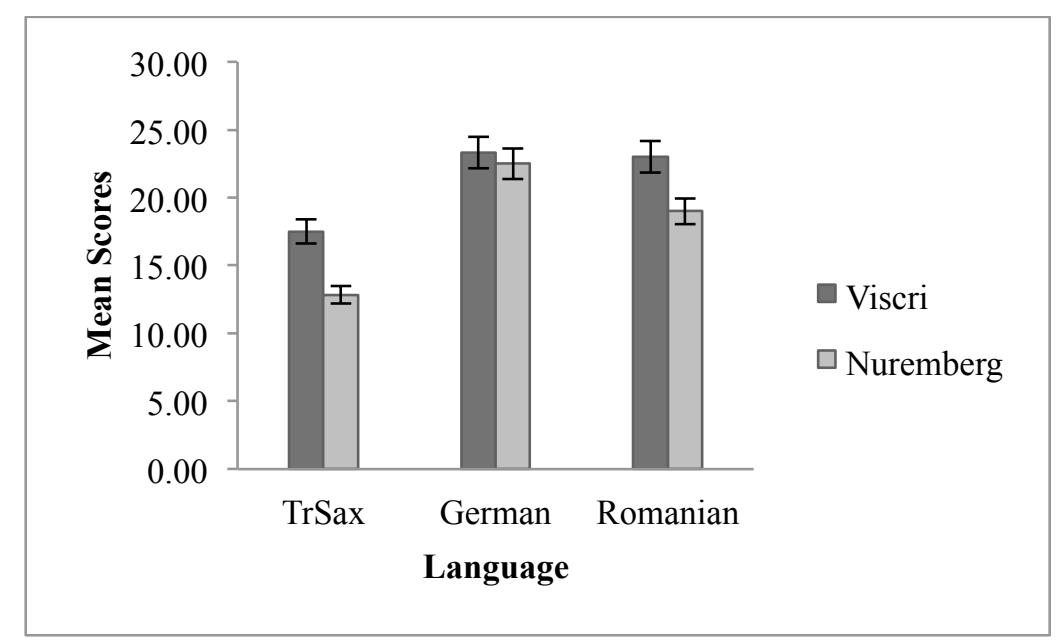

Figure 5. Mean Language Proficiency scores by site

The overall lower scores for $\operatorname{TrSax}$ are due to the questionnaire containing questions about literacy in each language, and none of the participants are literate in TrSax, which is only a spoken language, transmitted orally. The lower self-assessed proficiency in TrSax for the participants in Nuremberg might be connected to their ideologies about how the language should be spoken, rather than their actual level of proficiency. When asked about their language, some of the Nuremberg participants would say that they do not speak TrSax as well as they used to or that they do not speak as well as it is spoken in the homeland. The sociolinguistic interviews reveal that the TrSax community in Nuremberg counts about 150 members who are in close contact to each other, and all participants in Nuremberg have a TrSax partner, while only one of the participants in Viscri has a TrSax partner. Therefore, all the participants from Nuremberg use TrSax on a daily basis and their use of the language is not limited to just one (home) domain.

A significant interaction between Site and Language (chi squared $=12.77$ and $\rho=0.0016$ ) was detected when analyzing scores from the Language Use module, which indicates that there is a difference in how languages are used between Viscri and Nuremberg.

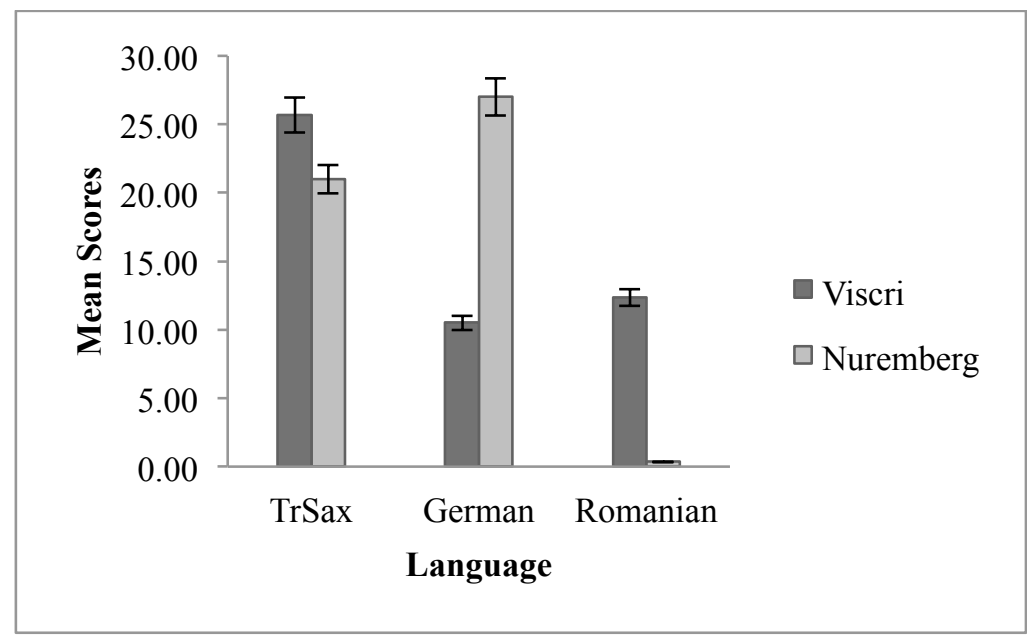

Figure 6. Mean Language Use scores by site 
Significant effects were detected for German $(\rho=0.018)$ and Romanian $(\rho=0.047)$ (by running the linear mixed effects model with each of the three languages as a reference language), but not for $\operatorname{TrSax}(\rho=0.23)$. German is used significantly more in Nuremberg than in Viscri, and Romanian is used significantly less in Nuremberg than in Viscri. However, these results are open for interpretation, because there is a disconnect between what participants estimated in the surveys and what they report during the sociolinguistic interviews. For example, based on the survey results shown in Figure 5 above, TrSax is used significantly more than German and Romanian among participants in Viscri, however there were only 15 speakers left at the time the data were collected, and only one of the speakers in this sample, speaker A5, uses TrSax with her partner at home (see Table 2 for further details on language use). The domains of use for TrSax have decreased drastically in the past 30 years: participants report using German and/or Romanian at home and in the wider community, instead of or along with TrSax. Furthermore, participants in Nuremberg had slightly lower scores for TrSax use as compared to participants in Viscri, however all the participants interviewed in Nuremberg have a TrSax partner and use TrSax at home (see Table 3 for more details).

5.2. Transylvanian SAXON AUX + V COMPlEXES. Summing up the results from the previous section, it becomes clear that participants from both sites are very similar in terms of linguistics attitudes towards all the languages they speak, proficiency in German and use of TrSax. Partici-pants in Nuremberg rate themselves as less proficient in Romanian than participants in Viscri, and report a very limited use of Romanian as compared to participants in Viscri, who report us-ing Romanian to a similar degree as German.

Going back to the initial hypothesis, I predicted that participants in Germany will show more German influence in their TrSax than participants in Romania in the form of a higher rate of $\mathrm{V}$-Aux constructions in subordinate clauses. I made these predictions based on the fact that participants in Germany have increased exposure to and use of German as compared to participants in Romania, which is confirmed by the questionnaire results. Furthermore, I factored in language attitudes as a possible predictor of the extent to which transferred constructions will be used, but no significant differences were found between participants from the two sites in terms of self-reported language attitudes. Preliminary results based on analyzed TrSax production data are shown in Figure 6 below and are based on 207 tokens. For the sake of this paper I will only present and discuss qualitative data. Participants labeled with A correspond to the group in Viscri and participants labeled with B are from the Nuremberg group.

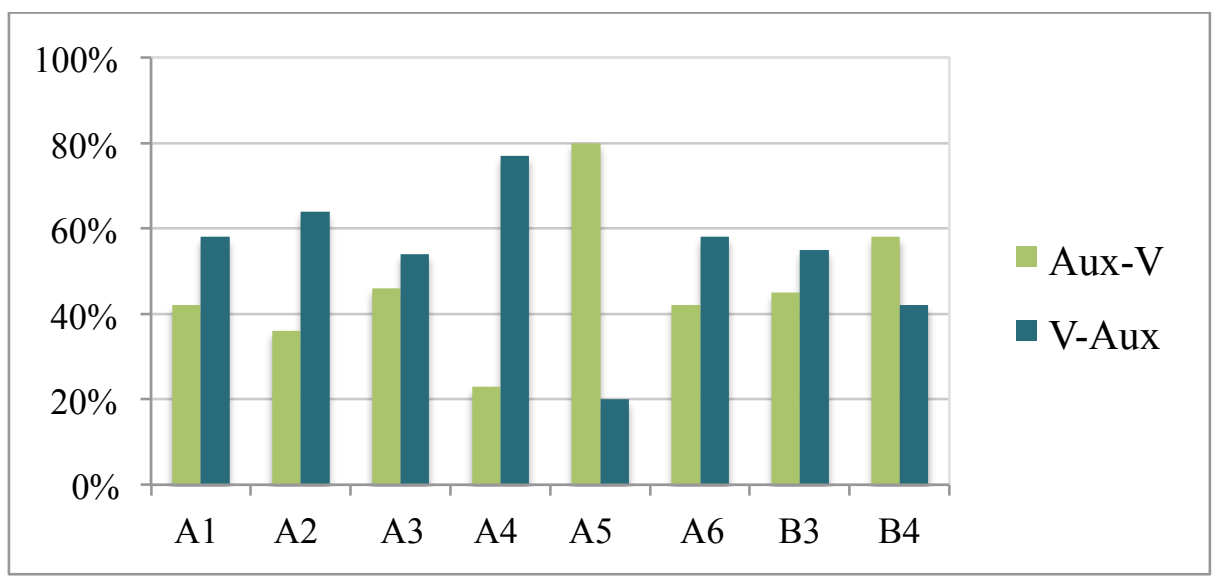

Figure 7. Patterns of Aux-V/ V-Aux variation in 8 speakers $(n=207)$ 
The difference in the use of Aux-V/ V-Aux construction is not significant for participants B3 and B4 (both from Nuremberg). I predicted that participants from Nuremberg would use more V-Aux constructions in subordinate clauses, however the prediction is not confirmed at this time. Significant differences were detected (based on an exact binomial test) for A4 and A5, with A4 using V-Aux significantly more than Aux-V $(\rho<0.05)$ and A5 using Aux-V significantly more than V-Aux $(\rho<0.05)$. A4 is a German teacher and reports using German at work and with friends (about $60 \%$ of weekly language use), TrSax with family (about $40 \%$ of weekly language use), and Romanian on limited occasions (about 10\%). A5 has a Romanian partner and reports using Romanian about $70 \%$ of the time in a regular week, TrSax with friends (about 20\%) and German on more limited occasion. Based on their reported language use and results, I would not reject the hypothesis that speakers who use more German will show more transferred (V-Aux) constructions in their TrSax, however further data is needed and a more in depth statistical analysis to establish how all these variables interact. Data I collected from four more participants from Germany need to be analyzed in order to determine if and how the groups differ. I discuss future research plans in the following section.

\section{Conclusions.}

In this article, I reported on the methodology I used to identify variables that distinguish two trilingual groups in order to explain contact induced syntactic variation and I presented preliminary results based on production data. I hypothesized that increased use (and exposure) of the dominant language in the community will influence how transferred and native constructions will be used, however there is not sufficient data at the time to confirm the hypothesis. Participants were remarkably similar in terms of language attitudes, and participants from both groups show the most positive attitudes towards TrSax, followed by German and then Romanian. Therefore language attitudes as evaluated with the BLP questionnaire are not a strong predictor of the extent to which transferred structures are used, but could explain in future research why participants are resisting change. While the BLP is a great tool for capturing information on participants' linguistic background, the results need to be treated with some caution and the information provided in the questionnaires should be evaluated in connection to the information provided in the sociolinguistic interviews. There is a discrepancy between what is reported in the interviews and what questionnaire scores reveal. This is partly connected to the questions in the questionnaire that are not applicable among all the languages (i.e. questions about literacy in a language), and partly to the reliability of self-reports. When it comes to language use some speakers may have reported their ideological view on language use, hence scores for TrSax were very high in both communities, even though the TrSax community in Viscri is restricted to just a handful of speakers.

6.1. FUTURE RESEARCH. As part of my upcoming dissertation, I plan to analyze data I collected in each of the languages participants speak to detected further features in TrSax that are susceptible to transfer and identify the source language for transfer. One possible area in $\operatorname{TrSax}$ that could reveal influences from German or Romanian is the clause structure. Because TrSax has more flexible word order than German and Romanian has flexible word order, TrSax speakers could align clause constituents after their dominant language. Language dominance can also be assessed with additional measures applied directly to production data (i.e. proficiency measures used in second language acquisition or child language acquisition) in order to complement ques-tionnaire scores and obtain a more holistic view of the trilingual speaker's linguistic profile. 


\section{References}

Backus, Ad, A. Seza Doğruöz \& Bernd Heine. 2011. Salient stages in contact-induced grammatical change: Evidence from synchronic vs. diachronic contact situations. Language Sciences 33(5). 738-752.

Bancu, Ariana. 2017. Word order variation and change in Transylvanian Saxon. University of Pennsylvania Working Papers in Linguistics 23(2). Art 3. https://repository.upenn.edu/pwpl/vol23/iss2/3.

Baptista, Marlyse, Susan A. Gelman \& Erica Beck. 2016. Testing the role of convergence in language acquisition, with implications for creole genesis. International Journal of Bilin gualism 20(3). 269-296.

Bottesch, Johanna. 2008. Rumänien. In Ludwig M. Eichinger, Albrecht Plewnia \& Claudia M. Riehl (eds.), Handbuch der deutschen Sprachminderheiten in Mittel- und Osteuropa. Tübingen. 329-392.

Clyne, Michael. 2003. Dynamics of language contact: English and immigrant languages. Cambridge: Cambridge University Press.

Corsale, Andrea, and Monica Iorio. 2014. Transylvanian Saxon culture as heritage: Insights from Viscri, Romania. Geoforum 52. 22-31.

Gertken, Libby M., Mark Amengual \& David Birdsong. 2014. Assessing language dominance with the Bilingual Language Profile. Measuring L2 proficiency: Perspectives from SLA. 208-225.

Gumperz, John J., and Robert Wilson. 1971. Convergence and creolization: a case from the Indo-Aryan/ Dravidian border in India. In Dell Hymes (ed.), Pidginization and creolization of languages. 151-167. Cambridge: Cambridge University Press.

Haig, Geoffrey. 2006. Linguistic diffusion in present-day East Anatolia: from top to bottom. In Alexandra I. Aikhenvald, and Robert M. Dixon (eds.), Areal diffusion and genetic inheritance: problems in comparative linguistics. 195-224. Oxford University Press.

Heath, Jeffrey G. 1984. Language contact and language change. Annual Review of Anthropology 13(1). 367-384.

Holzträger, Fritz. 1912. Syntaktische Funktion der Wortformen im Nösnischen. Doctoral dissertation. Universität zu Tübingen. Germany.

Kantarovich, Jessica, and Lenore A. Grenoble. 2017. Reconstructing sociolinguistic variation. Proceedings of the Linguistic Society of America 2. 27:1-15. https://doi.org/10.3765/plsa.v2i0.4080.

McClure, Malcolm M. 1973. A grammar of the Weingartskirchen dialect of Transylvanian German. Doctoral Dissertation. University of California at Berkeley.

Meyerhoff, Miriam. 2015. Turning variation on its head: Analysing subject prefixes in Nkep (Vanuatu) for language documentation. Asia-Pacific Language Variation 1(1). 78-108. https://doi.org/10.1075/aplv.1.1.04mey.

Nagy, Naomi. 2017. Documenting variation in (endangered) heritage languages: How and why?. Language Documentation \& Conservation Special Publication 13. 33-64.

Nagy, Naomi, Michael Iannozzi, and David Heap. 2017. Faetar null subjects: A variationist study of a heritage language in contact. International Journal of the Sociology of Language 2018(249). 31-47. https://doi.org/10.1515/ijs1-2017-0040.

Nagy, Naomi \& Alexei Kochetov. 2013. Voice onset time across the generations: a crosslinguistic study of contact-induced change. In Peter Siemund, et al (eds.), Multilingualism and llanguage contact in urban areas: Acquisition - development-teachingcommunication. 19-38. Amsterdam: John Benjamins. https://doi.org/10.1075/hsld.1. 
Nagy, Naomi G., Nina Aghdasi, Derek Denis, and Alexandra Motut. 2011. Null subjects in heritage languages: Contact effects in a cross-linguistic context. University of Pennsylvania Working Papers in Linguistics 17(2). 135-144.

Sapp, Christopher D. 2011. The verbal complex in subordinate clauses from medieval to modern German. Amsterdam: John Benjamins.

Tagliamonte, Sali A. \& Alexandra D’Arcy. 2007. Frequency and variation in the community grammar: Tracking a new change through the generations. Language Variation and Change 19(02). 390-412. https://doi.org/10.1017/S095439450707007X.

Tagliamonte, Sali A. 2006. Analyzing sociolinguistic variation. Cambridge University Press. Thomason, Sarah. G. 2010. Contact explanations in linguistics. In Raymond Hickey (ed.), The handbook of language contact. 31-47. Oxford: Wiley-Blackwell.

Wittenburg, Peter, Hennie Brugman, Albert Russel, Andreas Klassmann \& Han Sloetjes. 2006. ELAN: A professional framework for multimodality research. In Proceedings of LREC 2006, $5^{\text {th }}$ International Conference on Language Resources and Evaluation. 1556-1559.

Wurmbrand, Susanne. 2015. Verb clusters, verb raising, and restructuring. In Martin Everaert \& Henk van Riemsdijk (eds.), The Blackwell companion to syntax, 1-103. Oxford: WileyBlackwell. 